\title{
Consequences of inaccurate hepatitis $C$ virus genotyping on the costs of prescription of direct antiviral agents in an Italian district
}

This article was published in the following Dove Press journal:

ClinicoEconomics and Outcomes Research

14 September 2016

Number of times this article has been viewed

\author{
Ennio Polilli' \\ Valeria Cento ${ }^{2}$ \\ Umberto Restelli $i^{3,4}$ \\ Francesca \\ Ceccherini-Silberstein ${ }^{2}$ \\ Marianna Aragri ${ }^{2}$ \\ Velia Chiara Di Maio² \\ Antonina Sciacca' \\ Fiorenzo Santoleri ${ }^{5}$ \\ Paolo Fazii ${ }^{6}$ \\ Alberto Costantini ${ }^{5}$ \\ Carlo Federico Perno 2 \\ Giustino Parrutil \\ 'Infectious Diseases Unit, Pescara \\ General Hospital, Pescara, \\ ${ }^{2}$ Department of Experimental Medicine \\ and Surgery, University of Rome "Tor \\ Vergata", Rome, ${ }^{3}$ CREMS - Centre \\ for Research on Health Economics, \\ Social and Health Care Management, \\ Carlo Cattaneo - LIUC University, \\ Castellanza, Italy; ${ }^{4}$ School of Public \\ Health, Faculty of Health Sciences, \\ University of the Witwatersrand, \\ Johannesburg, South Africa; ${ }^{5} \mathrm{Hospital}$ \\ Pharmacy, Pescara General Hospital, \\ ${ }^{6}$ Microbiology and Virology Unit, \\ Pescara General Hospital, Pescara, Italy
}

Correspondence: Giustino Parruti Infectious Diseases Unit, Pescara General Hospital, Via Fonte Romana 8, 65I24

Pescara, Italy

Tel +39085 4252410

Fax +39085 4252499

Email parruti@tin.it

\begin{abstract}
Available commercial assays may yield inaccurate hepatitis $\mathrm{C}$ virus (HCV) genotype assignment in up to $10 \%$ of cases. We investigated the cost-effectiveness of re-evaluating $\mathrm{HCV}$ genotype by population sequencing, prior to choosing a direct acting antiviral (DAA) regimen. Between March and September 2015, HCV sequence analysis was performed in order to confirm commercial LiPA-HCV genotype (Versant ${ }^{\circledR}$ HCV Genotype 2.0) in patients eligible for treatment with DAAs. Out of 134 consecutive patients enrolled, sequencing yielded 21 $(15.7 \%)$ cases of discordant results. For three cases of wrong genotype assignment, the putative reduction in efficacy was gauged between $15 \%$ and $40 \%$. Among the eight cases for whom G1b was assigned by commercial assays instead of G1a, potentially suboptimal treatments would have been prescribed. Finally, for five patients with G1 and indeterminate subtype, the choice of regimens would have targeted the worst option, with a remarkable increase in costs, as in the case of the four mixed HCV infections for whom pan-genotypic regimens would have been mandatory. Precise assignment of HCV genotype and subtype by sequencing may, therefore, be more beneficial than expected, until more potent pan-genotypic regimens are available for all patients.
\end{abstract}

Keywords: HCV, HCV sequence analysis, HCV genotype, direct acting antiviral, treatment costs

\section{Introduction}

Currently available genotyping methods, based on reverse hybridization with subtypespecific primers and probes targeting the $5^{\prime}$-untranslated region $\left(5^{\prime}\right.$-UTR) and core regions (Versant ${ }^{\mathbb{}}$ HCV Genotype 2.0 system; Siemens Healthcare Diagnostics, Milan, Italy), as well as real-time PCR assays based on 5'-UTR and NS5B sequencing (Abbott HCV Genotype II assay; Abbott Diagnostics, Lake Forest, IL, USA), accurately differentiate major hepatitis $\mathrm{C}$ virus $(\mathrm{HCV})$ genotypes in the majority of cases and are widely used because of their technical simplicity and lower costs. ${ }^{1}$ Routine genotyping methods, however, may cause wrong, inaccurate, or incomplete assignment in up to $10 \%$ of cases, due to indeterminate results, mixed infections, wrong subtyping, and even wrong genotyping, as we recently reported. ${ }^{2}$ Misclassifications of $\mathrm{HCV}$ genotype were described in characterization of genotypes 5 and 6 and in subtyping of genotypes. ${ }^{2-6}$ Versant HCV Genotype 2.0 fails to identify genotype 1 subtype in $2.2 \%-7.4 \%$ of the cases. ${ }^{5}$ In particular, cause of misclassification was due to variability of $5^{\prime}$-UTR of HCV. This region is not appropriate for discriminating HCV strains at the subtype level and for distinguishing many genotype 6 samples from genotype 1 as well as for distinguishing subtypes within genotypes 1,2 , and $3{ }^{6}$ Incorrect assignments of genotype were associated with nucleotide polymorphisms in 
the $5^{\prime}$-UTR of HCV that may alter the ability of probe/primer of commercial assays to recognize viral strains. Indeterminate genotype results were reported for changes at positions 166 and 119 in genotype $2 \mathrm{~b}$ and 138,108 , and 99 in genotype $3 \mathrm{~h}$ of 5'-UTR of HCV.? As most of the currently available therapeutic options target HCV genotype 1 strains, treatment of other genotypes, in particular genotype 3 , is presently less efficient and more costly when directly acting antivirals (DAAs) are used. ${ }^{8}$ Reassessment of HCV genotype and subtype by sequencing prior to interferon-free regimens may reduce the risk of treatment failure and consequent undue pharmacological costs driven by inappropriate genotype characterization and may, therefore, turn out quite cost beneficial. ${ }^{2,9}$ We investigated the cost-effectiveness of re-evaluating HCV genotype by population sequencing, prior to choosing a DAA regimen among currently available options, in a mono-centric Italian cohort.

\section{Methods}

Between March, 2015, and September, 2015, at the Liver and Infectious Diseases Units of Pescara General Hospital, Italy, $\mathrm{HCV}$ sequence analysis was performed in order to confirm previous commercial assignment by a second-generation LiPA-HCV genotype assay (Versant HCV Genotype 2.0; Siemens Healthcare Diagnostics) in all consecutive candidates to treatment with DAAs. The local Health District Authority was requested to evaluate the possible benefits of the experimental procedure, and found it likely cost-effective and funded 200 consecutive assays for the purpose of this evaluation. Direct population sequencing was, therefore, performed for both NS5A and NS3 HCV genes at the University of Tor Vergata (Rome) through highly efficient home-made protocols as previously reported. ${ }^{2}$ Expert interpretation of mutations and sequence variants detected was also provided by the same source (University of Rome Tor Vergata) for each patient, to help in choosing the most appropriate and individualized regimen. The turnaround time allowance from sample dispatching to availability of assay results was set at a maximum of 3 weeks, to avoid undue delaying of treatments. For the purpose of the present study, in each case of resolved or discordant HCV genotype and/or subtype after sequencing, we calculated the difference in treatment costs between the most likely prescription that would have been possible on the basis of previously available commercial HCV genotype and subtype only, and the most likely prescription made possible by the availability of sequence results with expert interpretation. Interferon-free regimens were prescribed by attending specialists in accordance with current European Association for the Study of the Liver Guidelines and Italian Regulatory Agency
(AIFA) reimbursement requirements. ${ }^{10,11}$ Sustained virologic response 12 (SVR-12) was defined as undetectable viral load at 12 weeks after treatment. Expected efficacy for each prescribed regimen was derived by currently available published SVR-12 data for selected reference treatments. The costs considered in the analysis are direct medical costs (referred to 2015) related to each prescribed drug and/or regimen, retrieved from the Pharmacy Unit of Pescara General Hospital, and the genotypic test reimbursement received by the hospital from the Regional Health Service (ie, $€ 60$ for LiPA-HCV genotype assay and $€ 500$ for sequence analysis of HCV genotype). As a consequence, in the analyses of actual costs, reimbursements from the pharmaceutical companies were not considered, as the local pharmacy did not receive any refund sum as of date (February 8, 2016). The cost-effectiveness analysis was conducted considering the aforementioned direct medical costs and efficacy values for each patient in two scenarios: with the use of sequence analysis of HCV genotype vs use of LiPA$\mathrm{HCV}$ genotype assay. The time horizon considered was up to 12 weeks after HCV antiviral therapy conclusion.

To test the robustness of the results, a resampling bootstrapping analysis was performed, simulating 500 cohorts of 134 patients, randomly extracting patients from the base case scenario.

\section{Ethics}

The local Health Administrative Board in Chieti-Pescara reviewed in detail the study design, set up by the Infectious Diseases Staff at Pescara General Hospital. The study was thoroughly discussed by the Direzione Generale Strategica della Azienda Unità Sanitaria Locale di Pescara/Comitato Etico di Chieti/Pescara. A final authorization was granted by Direzione Generale Strategica della Azienda Unità Sanitaria Locale di Pescara early in 2015, as documented in issue Deliberazione del Direttore Generale number 319 March 16, 2015. Written informed consent was obtained from all participants.

\section{Results}

During the study period, 134 consecutive patients were included. Starting from January 2008, routine genotype and subtype assays were performed by Versant HCV Genotype 2.0. Sequencing yielded discordant or complementary information in $21(15.7 \%)$ cases. Among these, we found three $(2.3 \%)$ discordant genotypes, nine $(6.7 \%)$ discordant G1 subtypes, four (3\%) mixed infections, and five (3.7\%) indeterminate G1 subtypes that were then correctly attributed. Suboptimal treatment choice due to wrong genotype assessment in the three individual cases would have caused a reduction 


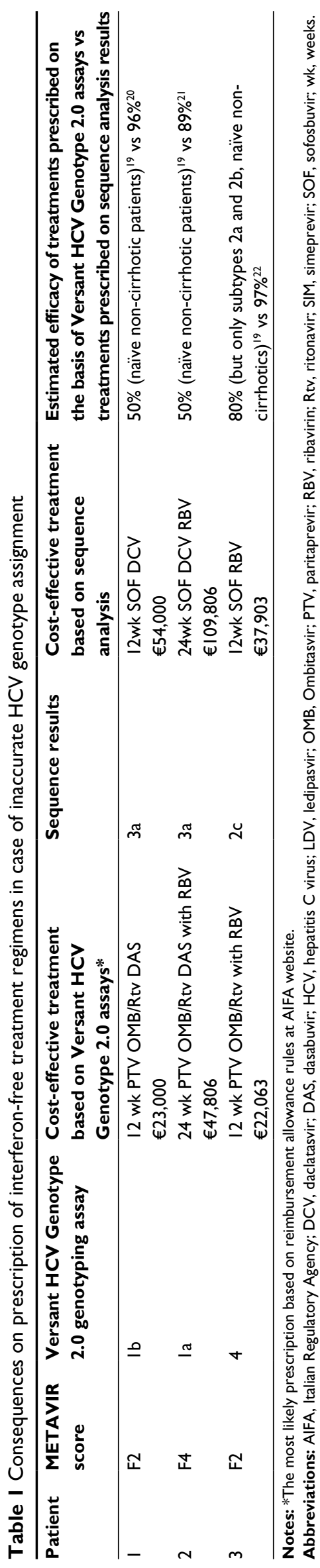

in efficacy which we gauged at our best, based on literature data, as ranging between $17 \%$ and $40 \%$ (Table 1). G1a was assigned by sequencing instead of G1b by commercial assays in eight out of nine cases with incorrect G1 subtype. This would have caused suboptimal treatment courses, with an expected decrease in efficacy from $5 \%$ to $7 \%$. Conversely, in the single opposite case (G1b assignment instead of G1a), the consequence would have been a slight increase in costs and the requirement of ribavirin use (Table 2). For patients with G1 and indeterminate subtype, the choice of regimens would have targeted the subtype 1a option, with a potential sensible increase in costs (Table 2). Finally, the possible consequences of inappropriate prescription due to mixed $\mathrm{HCV}$ infections are shown in Table 3. In these cases, pangenotypic regimens would be mandatory, with an increase in costs up to $€ 32,000$ per treatment.

The use of sequence analysis of HCV genotype, compared with LiPA-HCV genotype assay, would lead to a mean increase of efficacy $(+1.42 \%)$ and per capita costs $(+€ 1,280$ per patient). The results of the cost-effectiveness analysis are presented in Table 4.

The $2.4 \%$ of the sensitivity analysis simulations led to a dominance of sequence analysis of HCV genotype compared with LiPA-HCV genotype assay, reducing costs and increasing efficacy, while the remaining $97.6 \%$ of the results showed an increase in costs and efficacy (between $€ 1,269$ and $€ 4,617$, and $1.43 \%$ and $3.88 \%$ ) with incremental cost-effectiveness ratios between $€ 845 /$ efficacy unit and $€ 2,009 /$ efficacy unit.

\section{Discussion}

Although some studies found uninterpretable or indeterminate genotype assignations in varying percentages of assayed samples, especially in non-G1 HCV infections, ${ }^{4,12-16}$ the possible consequences of $\mathrm{HCV}$ genotype misclassification on treatments with DAAs were not yet evaluated and may have been perceived as a minor problem so far. However, in the new scenario of HCV therapy, the costs of genotyping by sequencing are definitely lower than those of DAA regimens, so that even a few treatment failures averted may make reassessing HCV genotype before DAAs very convenient. ${ }^{2}$ As a consequence, studies aimed at gauging the improvement of treatment outcomes by the systematic deployment of sequence genotype should be encouraged. We introduced mandatory sequencing assays of HCV prior to HCV therapy with DAAs at our site, and compared the results of all consecutive assays performed with previous routine genotype assessments, in an attempt to pinpoint all possible differences in treatment efficacy and on possible parallel cost savings obtained in this way. Although 


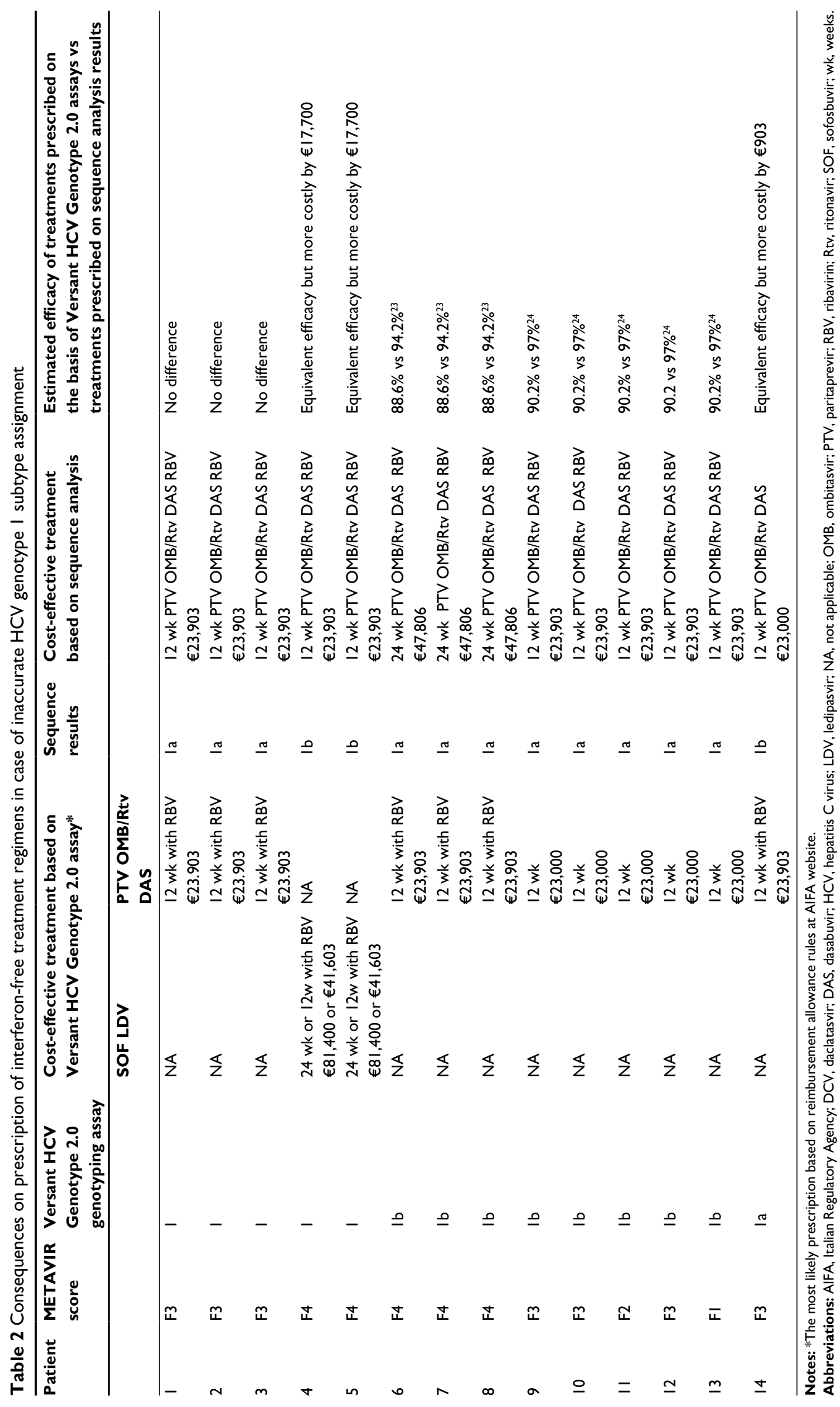




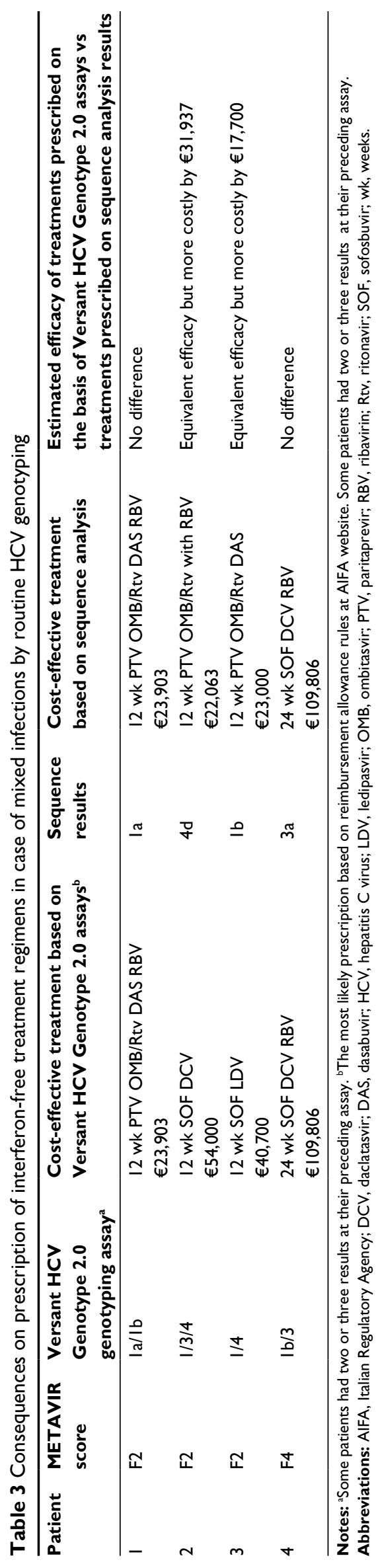

based at a single Italian site among the many authorized for the prescription of new treatments for $\mathrm{HCV}$, one major strength of our experimental design was the consecutive enrolment to sequence genotyping of all DAA eligible patients. This allowed a close estimate of the benefits of this investigational procedure in a relatively small sample of treated patients.

We found percentages of HCV genotype/subtype misclassification approximately in line with those reported by others, ${ }^{3,13,16-18}$ identifying four main groups of failures in routine genotyping. In the first group, we included three patients with misclassified genotypes. These would have had the potential of causing remarkable reductions in efficacy - up to $40 \%$ - of their respective DAA treatments, which means a high likelihood of inducing at least one treatment failure. This first group alone justified our effort and covered all study expenses. In the second and third groups were included several cases of indeterminate subtype or subtype misclassification. These would not have caused a significant reduction in efficacy; however, significant increases in costs would have occurred, especially for patients receiving a diagnosis of genotype 1a instead of $1 \mathrm{~b}$, and unduly longer and more toxic treatments. In these patients, the reduction in potential toxicity was an added and precious value on the top of averted expenses. In the last group of patients, mixed infections would have invariably induced the prescription of pan-genotypic regimens, causing a remarkable increase in costs, at least $50 \%$ greater than necessary.

The cost-effectiveness results show an overall increase in terms of efficacy due to the use of sequence analysis of $\mathrm{HCV}$ genotype along with a slight increase in terms of costs. The cost per unit of efficacy gained is difficult to interpret due to the lack of threshold values associated with SVR at 12 weeks for $\mathrm{HCV}$-infected patients.

The analysis performed does not consider the savings due to the mean efficacy increase and the need of further antiviral treatments and monitoring for patients not reaching SVR in the LiPA-HCV genotype assay scenario. Moreover, adverse events-related costs were not considered in the analysis due to the absence of interferon in the antiviral treatments considered (assuming similar safety profiles), which would, however, increase the direct medical costs due to retreatments. Further cost savings not considered in the analysis due to higher efficacy of treatments are those related to the lack of progression of $\mathrm{HCV}$ infection.

Future analyses should include a measurement of monitoring activities, adverse events management, and follow-up.

The main limit of the cost-effectiveness analysis performed is related to the short-term time horizon and the lack of use of effectiveness parameters that allow to interpret incre- 
Table 4 Results of cost-effectiveness analysis

\begin{tabular}{|c|c|c|c|c|c|}
\hline Scenario & Mean cost (€) & $\begin{array}{l}\text { Mean incremental } \\
\text { cost (€) }\end{array}$ & Mean efficacy (\%) & $\begin{array}{l}\text { Mean incremental } \\
\text { efficacy (\%) }\end{array}$ & $\begin{array}{l}\text { Incremental cost- } \\
\text { effectiveness ratio }\end{array}$ \\
\hline LiPA-HCV genotype assay & 41,338 & NA & 94.98 & NA & NA \\
\hline HCV genotype sequencing & 42,618 & $+1,280$ & 96.40 & +1.42 & 899.6 \\
\hline
\end{tabular}

Abbreviations: $\mathrm{HCV}$, hepatitis $\mathrm{C}$ virus; NA, not applicable.

mental cost-effectiveness ratio of technology use based on national recognized thresholds (ie, quality adjusted life years).

Overall, our experience highlights the importance and convenience of accurate $\mathrm{HCV}$ genotyping before current DAA regimens. If wrong or incomplete, $\mathrm{HCV}$ genotype information would have caused a preventable risk of treatment failure. The relatively low incremental costs of HCV sequence analysis compared with the current costs of DAAs suggests that precise assignation of HCV genotype and subtype by sequencing may be beneficial until new and more potent pan-genotypic regimens will be available for all patients. Therefore, for a personalized and tailored therapy, genotype by sequencing should be performed in advance of first-line treatment with DAAs.

\section{Conclusion}

Further analyses on the cohort, considering a longer time horizon, should investigate if, as potentially suggested by the results of the analysis presented, the use of sequence analysis of HCV genotype would lead to a decrease in direct medical costs for the treatment of HCV-infected patients, due to savings for the lower number of retreated patients and lack of disease progression. Further research is warranted.

\section{Disclosure}

The authors report no conflicts of interest in this work.

\section{References}

1. Yang R, Cong X, Du S, Fei R, Rao H, Wei L. Performance comparison of the versant HCV genotype 2.0 assay (LiPA) and the Abbott realtime $\mathrm{HCV}$ genotype II assay for detecting hepatitis C virus genotype 6. J Clin Microbiol. 2014;52(10):3685-3692.

2. Ceccherini-Silberstein F, Di Maio VC, Aragri M, Ciotti M, Cento V, Perno $\mathrm{CF}$. Hepatitis $\mathrm{C}$ virus gene sequencing as a tool for precise genotyping in the era of new direct antiviral agents. Hepatology. 2016;63(3):1058-1059.

3. Guelfo JR, Macias J, Neukam K, et al. Reassessment of genotype 1 hepatitis $\mathrm{C}$ virus subtype misclassification by LiPA 2.0: implications for directacting antiviral treatment. J Clin Microbiol. 2014;52(11):4027-4029.

4. Larrat S, Poveda JD, Coudret C, et al. Sequencing assays for failed genotyping with the versant hepatitis $\mathrm{C}$ virus genotype assay (LiPA), version 2.0. J Clin Microbiol. 2013;51(9):2815-2821.

5. González V, Gomes-Fernandes M, Bascuñana E, et al. Accuracy of a commercially available assay for HCV genotyping and subtyping in the clinical practice. J Clin Virol. 2013;58(1):249-253.

6. Murphy DG, Willems B, Deschenes M, Hilzenrat N, Mousseau R, Sabbah S. Use of sequence analysis of the NS5B region for routine genotyping of hepatitis $\mathrm{C}$ virus with reference to $\mathrm{C} / \mathrm{E} 1$ and $5^{\prime}$ untranslated region sequences. J Clin Microbiol. 2007;45(4):1102-1112
7. Pollicita M, Cento V, Paba P, Perno CF, Ciotti M. Nucleotide polymorphisms in the $5^{\prime} \mathrm{UTR}$ region of HCV can affect the ability of two widely used assays to assign an HCV genotype. JVirol Methods. 2013;193(1): 205-208.

8. Zeuzem S, Dusheiko GM, Salupere R, et al. VALENCE Investigators. Sofosbuvir and ribavirin in HCV genotypes 2 and 3. N Engl J Med. 2014;370(21):1993-2001

9. AASLD/IDSA/IAS-USA. Recommendations for testing, managing, and treating hepatitis C. Available from: http://www.hcvguidelines.org. Accessed September 2015.

10. EASL. Recommendations on treatment of hepatitis C. Available from: http://www.easl.eu/research/our-contributions/clinical-practiceguidelines. Accessed September 2, 2015.

11. AIFA-AISF. Documento di indirizzo dell'Associazione Italiana per lo Studio del Fegato per l'uso razionale di antivirali diretti di seconda generazione nelle categorie di pazienti affetti da epatite $\mathrm{C}$ cronica ammesse alla rimborsabilità in Italia [Document for the rational use of second generation direct antivirals in chronic hepatitis $\mathrm{C}$ patients approved for reimbursement in Italy]. Available from: http://www. agenziafarmaco.gov.it. Accessed October 5, 2015.

12. Avó AP, Agua-Doce I, Andrade A, Pádua E. Hepatitis C virus subtyping based on sequencing of the $\mathrm{C} / \mathrm{E} 1$ and NS5B genomic regions in comparison to a commercially available line probe assay. J Med Virol. 2013;85(5):815-822.

13. Bouchardeau F, Cantaloube JF, Chevaliez S, et al. Improvement of hepatitis $\mathrm{C}$ virus (HCV) genotype determination with the new version of the INNO-LiPA HCV assay. J Clin Microbiol. 2007;45(4):1140-1145.

14. Cai Q, Zhao Z, Liu Y, Shao X, Gao Z . Comparison of three different $\mathrm{HCV}$ genotyping methods: core, NS5B sequence analysis and line probe assay. Int J Mol Med. 2013;31(2):347-352.

15. Chevaliez S, Bouvier-Alias M, Brillet R, Pawlotsky JM. Hepatitis $\mathrm{C}$ virus (HCV) genotype 1 subtype identification in new $\mathrm{HCV}$ drug development and future clinical practice. PLoS One. 2009;4(12):e8209.

16. Vaghefi P, Marchadier E, Dussaix E, Roque-Afonso AM . Hepatitis C virus genotyping: comparison of the Abbott RealTime HCV Genotype II assay and NS5B sequencing. Pathol Biol (Paris). 2010;58(2):175-178.

17. Quer J, Gregori J, Rodríguez-Frias F, et al. High-resolution hepatitis $\mathrm{C}$ virus subtyping using NS5B deep sequencing and phylogeny, an alternative to current methods. J Clin Microbiol. 2015;53(1):219-226.

18. Benedet M, Adachi D, Wong A, et al. The need for a sequencing-based assay to supplement the Abbott $\mathrm{m} 2000$ RealTime HCV Genotype II assay: a 1 year analysis. J Clin Virol. 2014;60(3):301-304.

19. Lawitz E, Sullivan G, Rodriguez-Torres M, et al. Exploratory trial of ombitasvir and ABT-450/r with or without ribavirin for HCV genotype 1, 2, and 3 infection. J Infect. 2015;70(2):197-205.

20. Nelson DR, Cooper JN, Lalezari JP, et al. All-oral 12-week treatment with daclatasvir plus sofosbuvir in patients with hepatitis $\mathrm{C}$ virus genotype 3 infection: ALLY-3 phase III study. Hepatology. 2015;61(4):1127-1135.

21. Sulkowski MS, Gardiner DF, Rodriguez-Torres M, et al. Daclatasvir plus sofosbuvir for previously treated or untreated chronic HCV infection. N Engl J Med. 2014;370(3):211-221.

22. Lawitz E, Mangia A, Wyles D, et al. Sofosbuvir for previously untreated chronic hepatitis C infection. N Engl J Med. 2013;368(20):1878-1887.

23. Poordad F, Hezode C, Trinh R, et al. ABT-450/r-ombitasvir and dasabuvir with ribavirin for hepatitis C with cirrhosis. N Engl J Med. 2014;370(21): 1973-1982.

24. Ferenci P, Bernstein D, Lalezari J, et al. ABT-450/r-ombitasvir and dasabuvir with or without ribavirin for HCV. N Engl J Med. 2014;370(21): 1983-1992. 
ClinicoEconomics and Outcomes Research is an international, peerreviewed open-access journal focusing on health technology assessment, pharmacoeconomics and outcomes research in the areas of diagnosis, medical devices, and clinical, surgical and pharmacological intervention. The economic impact of health policy and health systems organization also constitute important areas of coverage. The manuscript management system is completely online and includes a very quick and fair peer-review system, which is all easy to use. Visit http://www.dovepress.com/testimonials.php to read real quotes from published authors.

Submit your manuscript here: https://www.dovepress.com/clinicoeconomics-and-outcomes-research-journal 